The Royal Institution of Naval Architects

\title{
Marine Design
}

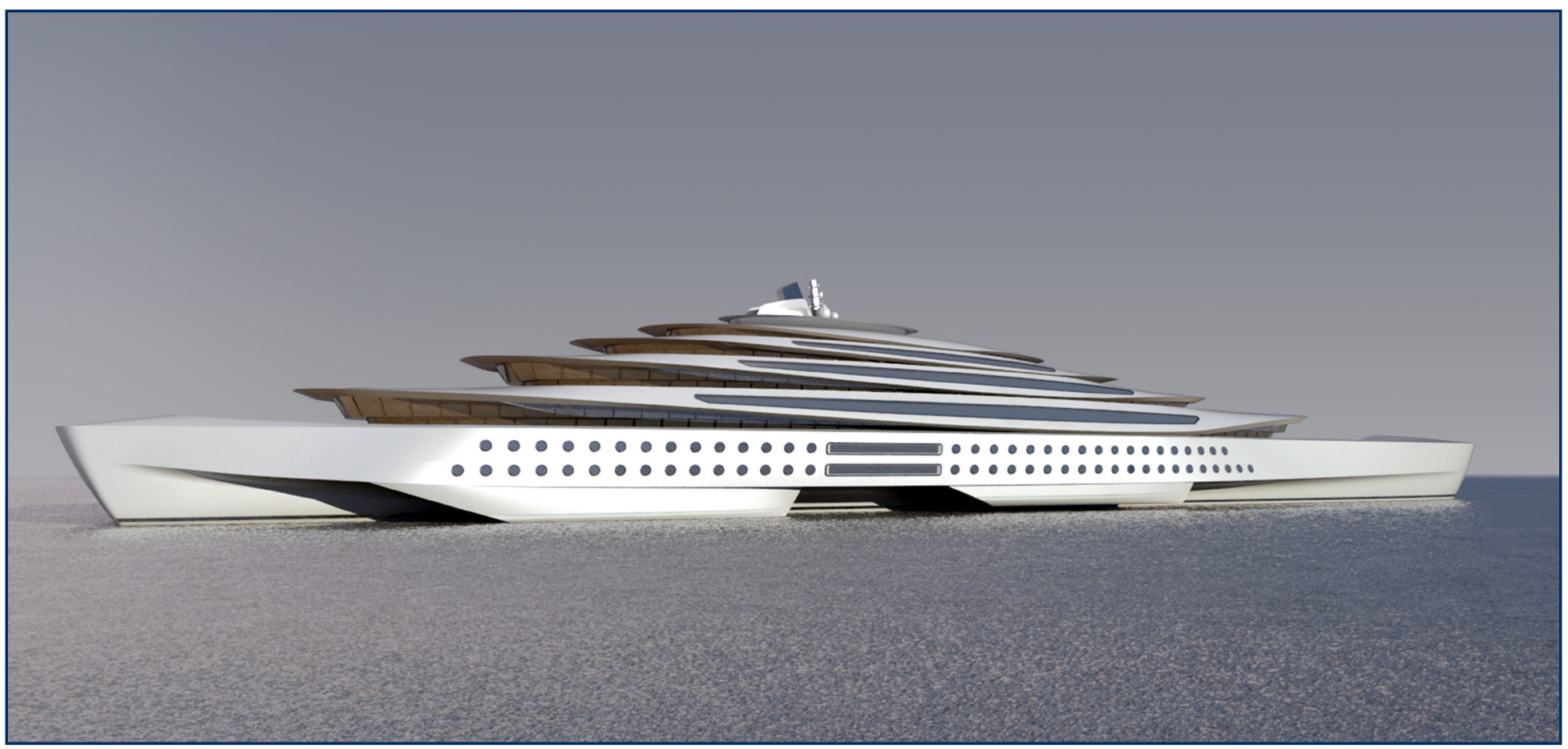

International Conference on Marine Design

3-4 September 2014, Coventry, UK

Supported by:

Coventry

University
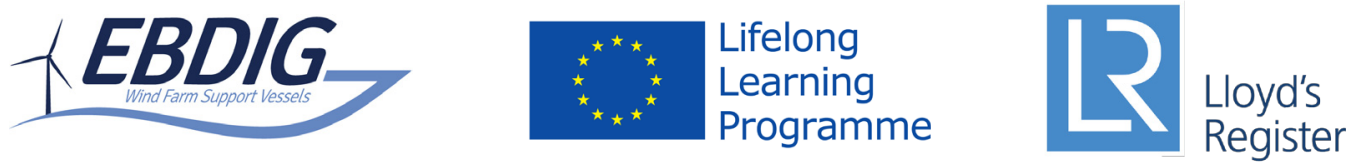

www.rina.org.uk/marine_design2014

For further information visit:

Call Jade on +44 (0) 2072354622 or email conference@rina.org.uk 
08.30-09.00

COFFEE \& REGISTRATION

$09.05-09.30$

KEYNOTE: H2020- THE OPPORTUNITIES FOR INNOVATION IN THE EUROPEAN MARINE INDUSTRY, Ronald Vopel, Research Programme Officer, Directorate-General for Research and Innovation, European Commission

$09.30-10.00$

\section{EUROPEAN BOAT DESIGN INNOVATION GROUP: THE MARINE DESIGN} MANIFESTO

Sean McCartan, B Verheijden, Coventry University, UK. M Lundh, M Lutzhoft, Chalmers University, SWEDEN. D Boote, Genoa University, ITALY. J.J. Hopman, F.E.H.M. Smulders, Technical University of Delft, NETHERLANDS, $K$ Norby, Oslo School for Architecture and Design, NORWAY. A manifesto is a published verbal declaration of the intentions, motives, or views of an issue. It accepts a previously published opinion and promotes a new idea with prescriptive notions for carrying out changes that the authors believe should be made. Marine Design is presented as an interdisciplinary holistic approach to boat design, based on the methodologies of Industrial Design, which are informed by both Human Factors and Engineering. The authors as experts in their respective disciplines present the Boat Design Manifesto as a framework for innovation within the marine industry. In every professional field there are definitive texts, this paper provides advocacy for Marine Design, an interdisciplinary approach in its infancy. On advocacy within the field of design, Mario Piazza reviewed a manifest of 100 years of social design manifestos. Informed by this, the authors review a number of key Industrial Design manifestos in the context of Marine Design. They then present a 10 point manifesto with contextual examples.

\section{$10.00-10.30$ \\ HUMAN SYSTEM INTEGRATION WITHIN A MULTIDISCIPLINARY SHIP} DESIGN TEAM: AN INSIDE VIEW

Chris Greenbank, BMT Reliability Consultants Ltd, UK. Dale Richards, Coventry University, UK. This paper presents the Human Systems Integration (HSI) view from within a multidisciplinary ship design team, and highlights the practical challenges and opportunities of adopting a HSI approach to ship design. An Optimised design that considers all aspects of efficiency is an almost intangible aspiration. However, this paper outlines the benefit of adopting a structured HSI process that addresses factors that have not only a design impact, but also benefits in terms of reducing total life cost and improvements in safety. Systems are not just metal, plastic and lines of code - the human is as much a part of the system as anything else. Adopting a HSI approach affords a more structured approach which often allows issues to be addressed early in a programme when it is more cost effective to make changes, rather than attempting to address human issues as they suddenly arise later in the process. A key element to this is balancing the user-centred approach with the real-world constraints of the project to achieve an optimum outcome for the client and the Seafarers who will live and work on the ship.

\subsection{0-11.00 ENABLING A SERVICE DESIGN PERSPECTIVE FOR SHIP DESIGN}

Etienne Gernez, Kjetil Norby, Birger Sevaldson, Oslo School for Architecture and Design, NORWAY

As user oriented perspectives are increasingly important in complex ships design processes there is a need to further develop human centered processes for collaborative design of ships. Service design and system oriented design are two new disciplines emerging from human centered design practices that may have interest for ship design. The Oslo School for Architecture and Design is now launching a PhD research project together with DNV GL to explore how the process of designing a ship can be supported and improved by adopting a service design and system oriented design perspective. The project is building on top of DNV GL's global involvement in Ship design verification and Ship design consulting with multidisciplinary innovation projects and transforming technology forecasting.

\subsection{0-11.30 COFFEE}

\subsection{0-12.00 MARINE DESIGN AND CULTURAL FORM}

Bruce Woods Dip ID, Massey University [Rtd], NEW ZEALAND
The author investigates the relationship between the stylistic force of cultural form and the contemporary Yacht [both Sail and Motor-Yacht]. He argues that this market is currently dominated by Western or Quasi-Western "High tech" generated forms to a degree which results in a dominant, boring, predictable and distorted set of stylistic paradigms. The result is a dearth of creativity and culturally relevant 3D form applied to the development of the Mega-yacht where the latter is, in a real sense a dominant measure of expression within the Marine Industry. Further that new paradigms would quickly become more recognisable relevant and acceptable to the owners conscious or unstated purposes, than their current obsession with stylistic elements which are fundamentally based on Western pre-conceptions, although the latter in a real sense provide a crude expression of an owners objectives in terms of status. The author argues that stylistic approach based on indigenous cultural forms, would generate a more meaningful visual statement of status and that this would provide more relevant creative and exciting design.

\subsection{0-12.30 THE POTENTIAL OF SURFACE PATTERN DESIGN IN THE AESTHETIC} DEVELOPMENT OF SUPERYACHT HULLS

Tom Nelson, Bob Verheijden and A Barrett, Coventry University, UK. Superyachts spend a large proportion of their existences in-dock, stationary aside from the movement of the water. We can therefore justify analysing them within the context of architecture, where buildings with such vast expanses of unbroken white surface are rarely seen. When such instances do occur, criticism soon follows - the Benthem Crouwel Wing of the Stedelijk Museum in Amsterdam has been dubbed "The Bathtub", and is widely derided. Whilst no such formalised and directed criticism of superyacht design exists as yet, there is clearly an opportunity for a rethink. This paper summarises research and development activities, where in-depth visual analysis of contemporary architecture has informed design output. The conclusion of this paper is a methodology for expansive surface treatment. This methodology (which advocates the orchestration of colour, transparency, translucency, opacity, texture, graphic design, relief, materials science, process, geometry, light, shadow, reflection, pattern, tessellation, wrapping, flexibility, kinetics, ageing, structure and biomimicry to break up surfaces) has informed a number of design projects, the results of which have been analysed within the context of both the superyacht industry and architectural practice.

$12.30-13.30$

$13.30-14.00$

\section{LUNCH}

Nina Kaehler, Fenna van de Merwe, Peter Securius, DNV GL, GERMANY. This paper presents the developments in the EU funded research project Cyclades (Crew-centred Design and Operations of Ships and Ship Systems). Cyclades aims to improve the current lack of implementation of UCD principles in workspace and equipment design. It is expected that better access to information regarding user centered design (UCD) will improve the design of workspaces onboard and thereby reduce the likelihood for human error. In the Cyclades project, a web-based framework is being developed that aims to make the existing information (i.e., guidelines, tools and methodologies) regarding UCD more accessible to those who are designing and ordering equipment and ship workspaces. This paper provides insight into how a piece of equipment will be designed using human centered information that will be retrievable from the framework.

$14.00-14.30$

AN INDUSTRIAL DESIGN APPROACH IN THE DEVELOPMENT OF A HARBOUR TUG CONSOLE

Bart Smit, Damen, NETHERLANDS. This paper describes the full design case of a redesigned bridge console, suitable for different types and sizes of DAMEN tugs to enhance a safe and comfortable working environment for its users. The Industrial Design approach for this design case started off by identification of a design opportunity by means of observational studies. By means of various qualitative research methodologies the desires, needs, wishes and demands of the users were collected. The ideation phase lead to multiple ideas which were tested and validated according to the rules and regulations. This resulted in the tug bridge design concept. This concept was tested by means of rapid prototyping and full scale mock-ups to be tested with users to optimise the design. Finally the product was built and installed on a DAMEN tug to be used permanently. This design was strongly focussed towards human factors in ship design in order to improve working procedures and safety on board the vessel.

$14.30-15.00$

CREATING A NEW DISTINCTIVE IDENTITY FOR A RANGE OF OFFSHORE VESSELS USING AN INDUSTRIAL DESIGN APPROACH

Marnix de Monchy, Damen, NETHERLANDS. Like in the car industry the user and owner of the vessel tend to identify themselves more and more with the vessel they work with. From an Industrial Design point of view this new offshore range was developed. First the vessel was taken out of the maritime and naval architecture design context. It was established like a product with the possible users and owners in mind. By implementing market research and using the design methods of metaphors, mood boards and SWOT analysis, a distinctive Offshore range was created. From the first model to the first PSV sailing around feedback and the related improvements were implemented.

$15.00-15.30$

SMALL PASSENGER CRAFT AND WATER TAXIS: AESTHETIC AND FUNCTIONAL ASPECTS OF DESIGN

A.Nazarov, A.Jabtanom, N.Charatsidis, Albatross Marine Design, THAILAND. Paper presents retrospective of problems involved in design and styling of small passenger boats, intended for inland and costal transportation such as tourist vessels, shuttle ferries, water taxis, diveboats based on design experience of Albatross Marine Design. Historical and cultural considerations are given with some samples representing traditional passenger craft from different parts of the world. The phenomena of water taxi as integral part of today's urban environment is revived in terms of consumer expectations and trends. Different concepts are reviewed including monohull craft, catamarans, hydrofoil, ACV, WIG etc. Weighted criteria are offered to evaluate applicability of those concepts for small passenger craft for particular tasks. Ergonomics of small passenger craft is studied in terms of feasible dimensions and possible compromise with requirements for bigger ships. Typical interior layouts are discussed with criteria proposed to assess its efficiency. Seating arrangements, boarding options, luggage storage areas etc. for comfort and safety are analyzed. Special attention given to accessibility for passengers with disabilities or mobility restrictions. Application of color schemes and art graphic as important features of exterior styling and customization in mass production world is presented. Regulatory aspects are reviewed giving the comparison of requirements to small passenger craft in some jurisdictions.

\section{$15.30-16.00$}

\section{COFFEE}

$16.00-16.30$

SHIP BLOCK DIVISION

Ajay Asok Kumar, ClassNK, JAPAN, Kazuhiro Aoyama, University of Tokyo, JAPAN

Block division planning is an important stage in the manufacturing design of ship hull structure and similar steel structures. During block division planning various factors such as crane capacities, hull structural arrangements, outfitting arrangements, material availability etc., must be considered simultaneously. At an early design stage, detailed information on these factors or constraints might not be certain. This uncertainty makes the generation of optimum block division planning difficult. In this paper, a block division planning system is proposed for the management of these uncertainties in the information at an early design stage. Using the system various block division plans can be generated, evaluated and ranked considering various factors affecting module division planning and their uncertainties. Based on the evaluation, some of the 'preferable' block division plans can be selected. The system is based on graph theory and fuzzy logic.

\subsection{0-17.00 VESSEL FIT OUT COST REDUCTION USING DIGITAL TECHNOLOGY AND MODULARITY}

Jules Morgan, KPM-Marine, UK. Inspired by WW2 liberty ship design and air craft interiors Sea-KaNo (meccano) has been designed and developed for fast fit using modular standard parts. Interiors meeting and exceeding all regulation. The stylish and functional habitation and bridge systems can be fitted in hours rather than weeks. The interior of a vessel can be changed to another use within a day giving the operator vessel flexibility. The design methodology accounts for asset adaptability and extended operating life, whilst taking into account the budget, quality and lean, regulation, primary and secondary function, modularity and regulation and legislation. The paper also details materials and techniques used in other industries giving significant reductions in weight and improvement in performance The paper details real life applications showing significant reductions in build cost and time whilst increasing the functionality and safety.

$17.00-17.30$

DESIGN DEVELOPMENT AND CONSTRUCTION OF 65' CATAMARAN YACHT A.Jabtanom, T.Phormtan, A.Nazarov, Albatross Marine Design, THAILAND Paper presents case study of 65 ' power catamaran project. Design process is reviewed, from hand sketching through CAD modeling to full-size prototyping and production. Interaction of naval architects, interior designers, engineering team, boatyard and customer, and also equipment suppliers is studied with lessons learned and proposed future collaboration improvements. The architecture of the craft is made without extremes, to provide attractiveness and practicality without impact of daily fashion fluctuations. Valuable insight on Asian interior styling is provided, allowing use of natural materials and traditional decorations where cultural knowledge is the key to create 'Asian look'. Solar-assisted concept is realized thorough extensive use of polar panels, allowing quiet and 'green' environments through integrated power management systems. Influence of regulations and standards on design is discussed in terms of space planning, watertight openings, deck safety, etc. covering some problems facing catamaran craft. Presented are results of sea trials showing measurable data on performance and comfort factors achieved. New developments in catamaran design are briefed, with few projects 45-105' currently in development. 
08.30-09.00

COFFEE \& REGISTRATION

$09.00-09.30$

\section{INDIVIDUALISTIC DESIGN}

Christopher Bottoms, De Voogt / Feadship, NETHERLANDS

Everyone is unique; we have our own dreams, cultures and expectations. Today, more and more yacht owners wish to express their individualism and at Feadship this is something we strongly encourage. Our presentation will give insight into how we realize our clients' dreams at Feadship. Designing fully custom yachts means we start the design process 'carte blanche', this requires us to understand the essence of yachting for the client. Our process allows us to create a strong connection between the client and the yacht because their personality is woven into the design at a conceptual level. By combining Feadship's design expertise with a strong, personal understanding of the client we can produce a custom yacht that is perfectly tailored to the client in every aspect.

$09.30-10.00$

IMPLEMENTATION OF ENVIRONMNETAL PSYCHOLOGY NETWORK MODEL AND BIOPHILIA PRINCIPLES, TO ADDRESS CREW HEALTH AND WELL-

BEING IN THE DEVELOPMENT OF A SWATH MOTHERSHIP CONCEPT FOR THE FAR SHORE WIND FARMS

MCCartan, L Moody, B Verheijden, Coventry University, UK. This paper presents a mothership concept design, developed through an implementation of the NetWork model of Environmental Psychology and Biophilic Design. The NetWork model encompasses both how and where work is done and how workers, processes and places are supported. It differs from previous models by focusing on the work that is to be done and how to enable it to be done most effectively. This knowledge informs the specification of furnishings, technologies, equipment and infrastructure that enable workers to make the best of wherever they work, to develop effective work practices, and to continue to adapt. This contrasts with the more traditional focus, which addresses only the places of work, and their efficient delivery and maintenance. The evolutionary basis for biophilia, is that contact with nature is a basic human need: not a cultural amenity, not an individual preference, but a universal primary need. The biophilia hypothesis and supporting research tells us that, as a species, we are still powerfully responsive to nature's forms, processes, and patterns

$10.00-10.30$

CONCEPT DESIGN SYNTHESIS OF AN OFFSHORE WIND TURBINE SUPPORT VESSEL

Patrick Couser, Bentley Systems France, Grégory Pelard, CNIM, FRANCE. Europe is the world leader in offshore wind power with forecasts predicting accelerating growth for at least the next ten years. The sites for new wind farm installations are moving further offshore and into deeper water. Prevision of infrastructure to support operations and maintenance is paramount to the viability of these wind farms; this requires vessels capable of both transporting personnel and equipment to the installations and then providing a stable platform from which maintenance tasks can be performed. Working from a definition of the vessel's operational requirements, a design space exploration has been undertaken using numerical simulation tools. The numerical simulation permits a greater range of design parameters to be quickly investigated at relatively low cost (compared with physical model testing). This enables a broader range of vessel options to be explored early in the design process as well as classifying which design parameters have the most significant influence. A review the methodology and numerical tools used is given as well as the resulting concept design outcome.

$10.30-11.00$

COFFEE

$11.00-11.30$

DEVELOPMENT OF INTERIOR DESIGN STRATEGIES AS AN INTEGRAL PART OF A MARINE PASSIVE DESIGN METHODOLOGY FOR PASSENGER VESSELS OPERATING WITHIN THE MEDITERRANEAN

S McCartan and C Kvilums, Coventry University, UK. This paper presents a study that focuses on the development of key passenger zones, namely the cabins, lounge and dining areas. Surface reflectance, room geometry and glazing type were varied in accordance with natural lighting principles, in an effort to maximize daylight utilization and reduce electrical loads. Thermal contributions of solar gain and the impacts of varying occupant densities were considered simultaneously in the overall energy assessment. A series of interior design proposals are presented that adopt these strategies to identify the potential gains and barriers to their implementation. Analysis of the results shows the potential of an integrative design process driven by daylight optimization to reduce operational costs. The predicted energy savings for a range of ship itineraries operating in the Mediterranean are discussed.

\subsection{0-12.00 DEVELOPMENT OF A PARAMETRIC MODEL FOR ANALYSING TEMPERATURE EFFECTS OF SOLAR RADIATION ON YACHTS}

Vivek Kumar, University of Genoa, ITALY, Guido Penco, Baglietto Shipyards, ITALY, Dario Boote, University of Genoa, ITALY, Tatiana Pais, University of Genoa, ITALY. This paper is in response to the need for a naval architect to deal with the engineering challenge of implementing solutions, which will enable dark coloured hulls, and still obtain excellent aesthetics. It contains an analytical study from experimental investigations, combined with a theoretical model for predicting temperatures. Parametric modelling has been used to study the effects of seasonal variations, different colours, different materials, and various solutions have been proposed to optimally negate the detrimental effects of high temperatures.

\section{$12.00-13.00$}

LUNCH

$13.00-13.30$

DESIGN-DRIVEN INNOVATION: NEXT GENERATION HIGH SPEED TRANSATLANTIC SUPERLINER

S McCartan, B Verheijden and P Crotty, Coventry University, UK, J Roy, BMT Nigel Gee, UK This paper reports on a transatlantic superliner design concept, which engages in Design-Driven Innovation to develop a new market sector for high speed multifunctional vessel to compete with both air freight and business class air travel in addition to the role of a superliner cruise ship. This design proposal offers the business traveller a personalised office space with global connectivity to make the journey a seamless extension of the working environment. This is specifically targeted at the creative design industries, with large design office spaces for collaborative working. There is also conference facilities and exhibition spaces, to facilitate product launches and client negotiations. The logistics role of the vessel gives the cruising passengers and business travellers a lower carbon footprint that a single function vessel, thereby engaging in green luxury. The vessel is based on the BMT ADX Express fast container ship Lo-Lo platform, capable of 37 Knots, offering a significant reduction in fuel consumption compared with conventional monohull platforms.

\section{$13.30-14.00$ \\ CRASH COMPATIBILITY IN THE DESIGN OF A TRIMARAN HIGH SPEED} CRUISE LOGISTICS FERRY (CLF)

C Bastien and S McCartan, Coventry University, UK, D Boote, T Colaianni, T Pais, University of Genoa, ITALY. Crash in high speed vessels has more in common with automotive accidents that those of slower larger vessels. The aims of the design project presented in this paper, was to develop a computer simulation model to predict, in the event of a 40knot crash of the CLF with both larger vessels and harbour structures, the structural damage, the post-crash flooding and the predicted injuries to ship crew and passengers throughout the vessel, for two distinctive bow types. The work involved reviewing and implementing established crash modelling and occupant protection simulation methodologies from the automotive sector. In terms of an injury prediction model, standing occupant models were used to simulated injuries and trauma at selected positions throughout the ship for the different accident scenarios. In order to develop a probabilistic prediction of fatalities or disabling injuries that would compromise escape and egress from the damaged vessel. The results were used to inform the iterative GA development process to improve evacuation and propose innovative active safety technology, to mitigate the risk of fatalities.

$14.00-14.30$

COASTAL PATROL INTERCEPTOR FOR WEST AFRICA

S Richardson, I Chapos, S McCartan, Coventry University, UK,

T Dobbins, ST Research, UK, J Hill, Trident Marine Ltd, UK, L Campbell, Lorne Campbell Design, UK.

This paper presents a coastal patrol interceptor concept developed using a User Centred Design approach. The vessel is based on a high speed trimaran platform, with an aluminium hull and composite superstructure. The outriggers provide improved stability in high sea states over a conventional planing hull. It will provide coastal patrol for fishery protection and piracy in the Gulf of Guinea. Several coastal patrol interceptors will operate from several ports along the coast to maximise operational range. The vessel exterior has an aggressive and sleek geometric design language, inspired by stealth aircraft and vessels. This gives the vessel a specific visual presence in the field of operation to help communicate its function.

$14.30-15.00$

DEVELOPMENT OF A UNIVERSAL DESIGN 30FT SAILING BOAT RACING CLASS FOR THE PHYSICALLY CHALLENGED

J Ruddiman, L Moody, S McCartan, EBDIG-IRC, Coventry University, UK. There are currently over 10 million disabled people in the UK, of which over 35,000 have learnt to sail through RYA Sailability schemes. They currently sail in a range of boats from single-handers to 3 man keel boats. These boats can be raced competitively from club to Olympic standard. This paper presents a racing yacht concept that has been developed using the principles of Universal Design, to enable disabled people and the ageing population to enjoy the excitement and challenge of close racing, without the issues that these users would experience with conventional yacht designs. The design was develop through dialogue with end user focus groups, and was informed by ethnographic analysis of a number of users with the range of physical abilities. This began with a study that explored the challenges and needs of disabled and ageing users within the sailing community, resulting in a design specification. On boats with multiple crew members, it became apparent that some tasks can be more easily handled by a less mobile sailor, and other tasks can be handled by someone more physically capable. Implementing the principles of Universal Design a range of user controllers were developed, with servo control systems for each of the sailing tasks on the boat. This range of controllers enable the vessel to be safely sailed by crew with the widest range of physical abilities, such that each crew member are equally able to carry out any of the boat sailing tasks. The option to use manual control supports the full range of mixed ability crew.

\subsection{0-15.30 COFFEE \& GENERAL DISCUSSION}

15.30-16.00 ROUGH LUXE HOUSEBOAT COMMUNITY PROPOSAL FOR THE ROYAL DOCKS IN LONDON

$N$ Cho, B Verheijden and T Nelson, EBDIG-IRC, Coventry University, UK. Future luxury values will be less about materialism and more about a personal experience. This paper presents a house boat community proposal of sustainable luxury houseboats for 2030, based on the growing movement of Rough Luxe. Passive Design is implemented through the use of louvres and natural ventilation, to reduces energy consumption. A light shelf and strategically placed mirrors help to optimise sunlight ingress, reducing the demand for artificial lighting. The open plan interior layout is informed by the solar azimuth angles to optimise use of the sunlight during different times of the day. Other sustainable materials implemented in the design are hemp for insulation and carbon-negative Novacem concrete for the pontoon. The living roof and walls not only minimise temperature fluctuation, but hold and filter water within their membranes. This rain water is collected to minimise consumption from supply.

$16.00-16.30$

DEVELOPMENT OF AN ONLINE LEARNING PLATFORM AND CPD MATERIAL FOR NAVAL ARCHITECTS AND PROJECT MANAGERS WORKING IN OFFSHORE WIND AND OIL AND GAS SECTORS

E Mangina, University College Dublin, IRL, A Ghassan and T Thompson, Coventry University, UK This paper presents the educational pedagogy and development process behind an e-learning platform that is used to transfer design innovation from the interior design and leisure marine industry, as well as Human Factors Integration from the automotive and aerospace sectors, into Wind Farm Support Vessels and associated mothership design. This is achieved through the development of a networking framework and three one day courses: WFSV design; WFSV mothership design; Human Factors Integration ( $\mathrm{HFI}$. The HFI course content is transferable to the Oil \& Gas industry. The main impact of these courses will be: greater understanding and awareness of the needs of the wind farm vessel industry and the market potential for ship builders; better trained commercial marine industry staff who are more aware of emerging technologies and techniques; marine industry standardised qualifications for Wind Farm Support Vessels. In attempting to achieve these aims, this paper discusses the benefits of peer tutoring in a design online learning environment.

\subsection{0-17.00 IMPLEMENTATION OF ECVETS INTO EBDIG-WFSV COURSE S} Sezai Isik and R Ziarati, Piri Reis University, TURKEY

The process of professional development whilst being continuous during a career, it is often considered as two stages: Initial Professional Development (IPD) and Continuing Professional Development (CPD). The intention is to seek accreditation for EBDIG-WFSV from the the Royal Institution of Naval Architects (RINA). Given the equal level of intended professional engagement in the design process between naval architects and marine designers, the EBDIG IPD/CPD training course learning outcomes will be mapped against RINA IPD development objectives for naval architects. In addition to the Accreditation of EBDIG-WFSV IPD/CPD courses by an international chartered professional body such RINA, the opportunity for EBDIG-WFSV to support vertical and horizontal mobility of higher education and VET in the long run necessitates the implementation of ECVETS into this mapping process so that both RINA and ECVET requirements are met. This paper reports on the development of the process of accreditation of EBDIG-WFSV applying a cross-referencing technique ensuring a right balance between marine engineering design naval architecture. 


\section{Marine Design}

3-4 September 2014, Coventry, UK

To register, simply complete all sections of this form and return it with your payment to:

The Conference Department, RINA

8-9 Northumberland Street

London, WC2N 5DA

TEL: +44 (0)20 72354622

FAX: +44 (0)20 72595912

E-MAIL: conference@rina.org.uk

TITLE (Dr, Mr, Eur Ing):

NAME (as it should appear on name badge):

\section{POSITION:}

COMPANY (as it should appear on name badge):

\section{INVOICE ADDRESS:}

\begin{tabular}{l}
\hline \\
\hline POSTCODE: \\
COUNTRY: \\
IELEPHONE: \\
EAX: \\
\hline E-MAIL:
\end{tabular}

CONTACT MAILING ADDRESS (if different):

\section{POSTCODE:}

\section{COUNTRY:}

TELEPHONE:

\section{FAX:}

\section{E-MAlL:}

\section{PLEASE INDICATE YOUR PREFERRED METHOD OF PAYMENT:}

I enclose a cheque for:

(made payable to RINA)

Please send me an invoice for :

Bank Transfer details enclosed for:

Please debit my credit card by:

Card Number: (Visa/Amex/Mastercard)

L
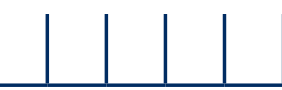

Expiry Date:
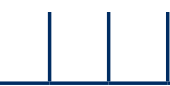

Signature:

How did you hear about this conference?

RINA MEMBERS:

$£ 400$

NON-MEMBERS:

$£ 450$

CONCESSIONS: (Retired/Students etc.) $\quad £ 300$

$£ 450$

$£ 500$

£300

PRINCIPAL AUTHOR

£125

ADDITIONAL AUTHOR

$£ 400$

$\mathbf{f} 125$

$£ 400$

The registration fee includes printed conference papers, lunch, refreshments, reception, $a C D$ of the papers and presentations after the conference, and VAT

\section{CONFERENCE PAPERS}

Delegates will receive a copy of the conference CD-ROM which will include the presentations, this will be posted out around 10-12 weeks after the conference.

Aditional copies of the conference papers will also be for sale after the event in both print and CD ROM versions. If you would like to order copies, please fill in the relevant sections.

I am unable to attend the conference, please reserve me

set(s) of Conference proceedings
Papers @ £110 (members)

CD ROM £110 (members)

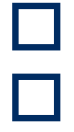

£130 (non-members)

£130 (non-members)
For a full list of the Institution's Conference papers, CD-ROM's and other technical publications please contact Billy Allen, Bookshop Assistant on +44 (0)20 72354622 or via e-mail at: publications@rina.org.uk

PAYMENTS

Payment must be made in pounds sterling by Eurocheque, cheque drawn on a bank with a UK branch address, credit card (VISA/Amex/Mastercard) or bank transfer. Please note RINA requires payment before the conference date.

Account Name: The Royal Institution of Naval Architects;

Account Number: 10042127; Account Code: 160016

Bank Address: Royal Bank of Scotland PLC, Belgravia Branch, 24 Grosvenor Place,

Bank Address: Royal Ban

London, SW1X 7HP, UK.

SWIFT No: RBOSGB2L

*VAT: Under UK Customs and Excise regulations delegates from all countries are required to pay VAT on any course taking place in the UK. Delegates from outside the UK may be entitled to reclaim this cost.

VENUE

The Venue for the conference is: Coventry University, Priory St, Coventry CV1 5FB

EVENING DRINKS RECEPTION

Following the end of day one $(03 / 09 / 14)$, delegates are invited to attend an evening drinks reception at the conference venue. Delegates will also be able to attend a wine reception at the end of day two $(04 / 09 / 14)$, celebrating the $30^{\text {th }}$ anniversary of boat design at Coventry University.

\section{ACCOMMODATION}

Upon registration you will be provided with details of a hotel booking service offering reduced rate accommodation for conference participants.

\section{CONTINUING PROFESSIONAL DEVELOPMENT}

RINA Certificates of Attendance will be issued at the event, which contributes towards the Institution's Continuing Professional Development Scheme. For further details regarding the scheme please contact Giuseppe Gigantesco, Director, Professional Affairs on Tel: +44 (0)20 72354622 or e-mail: membership@rina.org.uk

\section{STUDENT SPONSORSHIP}

A number of sponsored places at this conference are available for Student Members of RINA. For more information, please contact Yuen Yee Pang, Professional Affairs, RINA on Tel: +44 (0)20 72354622 or e-mail:ypang@rina.org.uk.

PROMOTIONAL OPPORTUNITIES

Why not use this conference to promote your company's products and services? It provides an excellent opportunity to increase your profile and to network with a highly focused audience. We offer a number of cost effective options, including various conference sponsorship packages, exhibition space and literature distribution. If you are interested in any of these promotional opportunities please contact the Conference Organiser to discuss your individual requirements.

\section{CANCELLATION CHARGES}

Cancellations received in writing two weeks before the event takes place will be subject to administration charge of £200+VAT. Cancellations received after this time cannot be accepted and are subject to the full event fee. Delegates may be substituted; however, this must be sent in writing and confirmed with the conference Co-ordinator. It may be necessary for reasons beyond our control to alter the content and timing of the programme. In the unlikely event that RINA cancels the event for any reason, our liability is limited to the return of the registration fee.

\section{DATA PROTECTION}

Personal data is gathered in accordance with the Data Protection Act 1998. Your details may be passed to other companies who wish to communicate with you offers related to your business activities. Please tick the box below where appropriate:

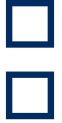
Please do not pass my information to any third party. I wish to receive email notification of future RINA events or publications If you have any questions regarding this or any other RINA event please contact, Jade Whitelaw, Conference Organiser, on:

Tel: +44 (0)20 7235 4622 Fax: +44 (0)20 72595912

E-Mail: jwhitelaw@rina.org.uk www.rina.org.uk/events 